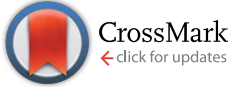

Cite this: RSC Adv., 2017, 7, 10323

Received 13th December 2016 Accepted 31st January 2017

DOI: 10.1039/c6ra28154k

rsc.li/rsc-advances

\section{Synthesis and optical and electrochemical memory properties of fluorene-triphenylamine alternating copolymer $\uparrow$}

\author{
Dechao Guo, ${ }^{a}$ Zhiyao Sun, ${ }^{\mathrm{b}}$ Shuhong Wang, ${ }^{\star \mathrm{b}}$ Xuduo Bai, ${ }^{\mathrm{a}}$ Laidi Xu, ${ }^{\mathrm{b}}$ Qun Yang, ${ }^{\mathrm{b}}$ \\ Ying Xin, ${ }^{b}$ Rongrong Zheng, ${ }^{b}$ Dongge $M a,{ }^{c}$ Xiaofeng Zhao ${ }^{b}$ and Cheng Wang*ab
}

\begin{abstract}
A highly soluble fluorene-triphenylamine conjugated alternating copolymer (PF-TPA) was designed and synthesized under Suzuki coupling reaction conditions in this work. The structure of the copolymer was characterized by Fourier transform infrared (FT-IR) spectroscopy, and hydrogen and carbon nuclear magnetic resonance $\left({ }^{1} \mathrm{H}-\mathrm{NMR},{ }^{13} \mathrm{C}-\mathrm{NMR}\right)$. The copolymer showed excellent thermal stability, and an onset decomposition temperature up to $443^{\circ} \mathrm{C}$. The optical and electrochemical properties of PF-TPA were investigated by using ultraviolet visible (UV-vis) absorption spectroscopy, photoluminescence (PL) spectroscopy, transient photocurrent responses and cyclic voltammetry (CV). The main absorption peak of PF-TPA appeared at $\lambda_{\max }=382 \mathrm{~nm}$ in the thin film and exhibits strong photoluminescence with maximum emission peaks centered at $464 \mathrm{~nm}$ in chloroform. The simulation results of the highest occupied molecular orbital (HOMO), lowest unoccupied molecular orbital (LUMO) and energy band gap are $-5.04,-2.22$ and $2.82 \mathrm{eV}$, respectively. A non-volatile rewritable flash memory device based on the active layer of PF-TPA was fabricated with the sandwich structure ITO/PF-TPA (102 nm)/Al. The memory device exhibits good electrical bistable resistive switching behavior, with low threshold voltage $\left(V_{\text {SET }} \sim-1.2 \mathrm{~V}\right.$ and $\left.V_{\text {RESET }} \sim 3.2 \mathrm{~V}\right)$, high ON/OFF current ratio in excess of $10^{3}$, high stability in retention time up to $10^{4} \mathrm{~s}$ and a number of read cycles up to 300 under a read voltage of $2 \mathrm{~V}$ in both ON and OFF states. The conductivity mechanism of the ITO/PF-TPA/Al device is discussed. The as-fabricated device exhibited good data retention characteristics, stability and reliability.
\end{abstract}

\section{Introduction}

Organic resistive random access memory (ORRAM) materials and devices have attracted a great deal of attention due to the emerging downscaling limits of the conventional inorganic Sibased technologies. ${ }^{1}$ Generally speaking, ORRAM devices are usually composed of two electrodes and a sandwiched active storage layer. Different from the traditional silicon-based inorganic memory cells, which store data by encoding each electrical circuit as " 0 " or " 1 " through discharge and charge, the typical ORRAMs store data as electrical bistability, namely, the memory device exhibits high and low conductivity responses (i.e., ON and OFF states) at the same time under the same external applied voltage. ${ }^{2}$ Among the reported materials for

${ }^{a}$ Key Laboratory of Functional Inorganic Material Chemistry, Heilongjiang University, Harbin 150080, P. R. China. E-mail:wangc_93@163.com

${ }^{b}$ School of Chemical Engineering and Materials, Heilongjiang University, Harbin 150080, P. R. China. E-mail: openair@163.com

${ }^{c}$ School of Materials Science and Engineering, South China University of Technology, Guangzhou 510640, P. R. China

$\dagger$ Electronic supplementary information (ESI) available. See DOI: $10.1039 /$ c6ra28154k resistor memory, organic materials have a prominent advantage of good processability and scalability, structure diversity, ultrafast write/read speed, mass data storage capacity, low power consumption, long-term stability, high-mechanical flexibility, simple device structure and the possibility for molecular design through chemical synthesis, making them a promising alternative or complementary technology to the inorganic semiconductor information technology. ${ }^{3}$ Memory devices based on organic materials have appeared as promising candidates for the next generation of memory devices.

In recent years, increasing attention has been paid to the application of organic materials in memory devices on account of their excellent properties. Large amounts of ORRAM devices have been fabricated using various organic materials, including polyimide (PI), ${ }^{4}$ polyaniline (PAN) ${ }^{5}$ polyvinylcarbazole $(\mathrm{PVK}),{ }^{6}$ polyfluorene (PF), ${ }^{7}$ poly(methyl methacrylate) (PMMA), ${ }^{8}$ polyvinyl alcohol (PVA), ${ }^{9}$ polystyrene (PS), ${ }^{10}$ poly(3-hexylthiophene) $(\mathrm{P} 3 \mathrm{HT}),{ }^{11}$ triphenylamine (TPA) ${ }^{12}$ polyvinylidene fluoride (PVDF), ${ }^{13}$ as well as combinations of functional components. Among them, it is well-known that the PF and TPA were considered to be the most versatile and promising candidate for memory applications due to their outstanding properties. 
$\mathrm{PF}$ and its derivatives have been employed in one of the most promising hole-transporting materials for organic light emitting diodes (OLEDs), ${ }^{14}$ organic field effect transistors (OFETs), ${ }^{15}$ organic solar cells, ${ }^{16}$ organic photovoltaics (OPVs), ${ }^{17}$ electrochromic (EC) devices ${ }^{18}$, organic memory devices (OMDs), ${ }^{19}$ and exhibited nonvolatile memory characteristics. Moreover, the PF was chosen as the memory materials due to also its very strong thermal and chemical stability, excellent photoluminescence quantum yields and high carrier mobility properties.

As one of the most efficient hole transporting materials, TPA and its derivatives have been particularly remarkable as a promising candidate for optoelectronic devices due to their low ionization potentials, high electron affinity, excellent electronic and mechanical properties, tridimensional steric and good UV-light harvesting properties. ${ }^{20}$ Thus, the TPA rich electronic group was introduced into $\mathrm{PF}$, which enhanced the thermal stability, HOMO energy level, the hole-transporting ability and reduce the energy barrier from ITO anode injection hole. Several studies on PF-TPA composite systems using nonvolatile memory devices have been reported so far. ${ }^{21}$ They have shown excellent nonvolatile memory characteristics, including rewritable flash memory behavior and write-onceread-many times (WORM) memory characteristics. In contrast to the reported literature, the copolymer structure of this content is simple and easily controlled by adjusting the monomer levels used for polymerization. The nitrogen atom of triphenylamine shown a positive electricity when it formed the cation radical. The oxygen atom on the methoxyl group is able to donate electron, and improve the ability of triphenylamine as an electron donor material to provide electron. After the triphenylamine containing methoxyl group was introduced into the main chain of fluorene, it is not only prevent the aggregation effect effectively between the polymer chains, but also improve the HOMO energy level, hole-transporting ability and thermal stability, and reduce the energy barrier from ITO anode injection hole.
In this paper, we first synthesized a conjugated alternating copolymer poly[(9,9-dioctyl)-2,7-fluorene-co- $\mathrm{N}$-4-methoxy-4,4'triphenylamine] (i.e., PF-TPA) by Suzuki coupling reaction. In this copolymer, the fluorene backbone serves as a conjugated channel for charge carriers, the TPA groups serve as an electron donor and hole transporting material. Then, to evaluate the memory performance of PF-TPA, the copolymer is sandwiched between ITO (indium-tin-oxide) anode and Al cathode as the electroactive layer to fabricate the ITO/PF-TPA/Al resistive switching memory device, and measured the current-voltage (I$V$ ) characteristic curve by a semiconductor device analyzer. The device exhibited a typical bistable electrical switching behavior and nonvolatile rewritable flash memory effect with a low threshold voltage $\left(V_{\mathrm{SET}} \sim-1.2 \mathrm{~V}, V_{\mathrm{RESET}} \sim 3.2 \mathrm{~V}\right)$, a high ON/OFF current ratio in excess of $10^{3}$ at $-1.2 \mathrm{~V}$ and a long retention time of more than $10^{4} \mathrm{~s}$ without any degradation. The memory performance tests demonstrated that the presence of ITO/PFTPA/Al memory device have low mistaking, fast read/write, good stability and reliability characteristics.

\section{Experimental}

\subsection{Materials}

Organic solvents and anhydrous sodium carbonate were purchased from Sinopharm Co. Ltd. The solvents used in this study were purified, dried and distilled under dry nitrogen. All of the other chemicals were purchased from Sigma-Aldrich and used with no further purification.

\subsection{Synthesis of $N, N$-bis(4-bromophenyl)-4-(1-methylpropyl)- benzenamine (M1)}

The synthesis of M1 was carried out using a palladium-catalyzed Buchwald-Hartwig coupling reaction. The synthetic route and the chemical structure of the monomer are shown in Scheme 1. The detailed procedure is described as follows: $p$-anisidine (1.67 $\mathrm{g}, 13.60 \mathrm{mmol}$ ) and 1-bromo-4-iodobenzene (8.46 g, 29.92<smiles>COc1ccc(N(c2ccc(Br)cc2)c2ccc(Br)cc2)c(OC)c1</smiles>

M1

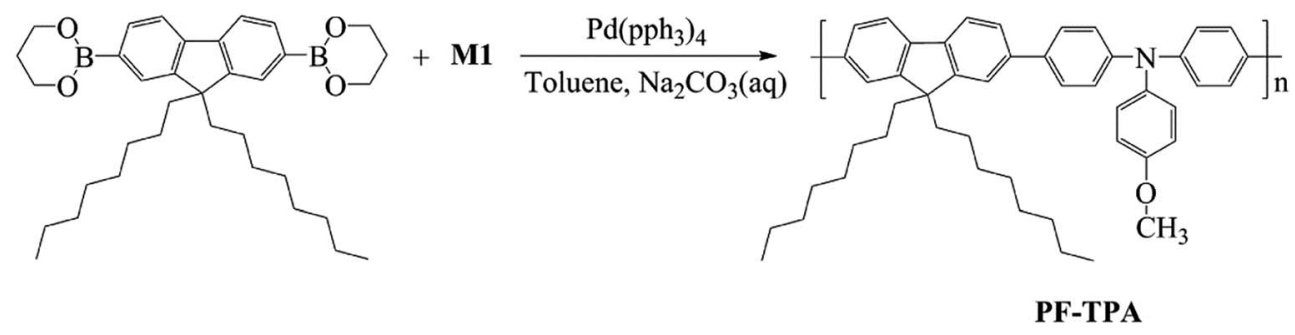

Scheme 1 Synthesis routes of monomer (M1) and copolymer (PF-TPA). 
mmol) was added to degassed toluene $(18 \mathrm{~mL})$ to form a clear solution. Then, tris(dibenzylideneacetone) dipalladium(0) $\left[\mathrm{Pd}_{2}(\mathrm{dba})_{3}\right]$ (0.125 g, $\left.0.136 \mathrm{mmol}\right), 1,1^{\prime}$-bis(diphenylphosphino) ferrocene (DPPF, $0.30 \mathrm{~g}, 0.544 \mathrm{mmol}$ ) and sodium tert-butoxide (3.92 $\mathrm{g}, 40.79 \mathrm{mmol}$ ) was added to above solution and the mixture was stirred under nitrogen atmosphere at $105{ }^{\circ} \mathrm{C}$ for 6 h. After cooled to room temperature, the reaction mixture was purified via extraction, concentration and column chromatography. The final product (M1), a yellow solid, was obtained after drying in vacuo with a yield of $4.87 \mathrm{~g}(82.8 \%)$.

The IR spectra of M1 were shown in Fig. S1, $\uparrow$ the peak at 1881 and $822 \mathrm{~cm}^{-1}$ can be attributed to the para-substituted benzene of triphenylamine. The peak at 1285 and $1309 \mathrm{~cm}^{-1}$ can be attributed to the stretching vibration of $\mathrm{C}-\mathrm{N}$. The peak at 1240 $\mathrm{cm}^{-1}$ can be attributed to the stretching vibration of $\mathrm{Ar}-\mathrm{O}$. Moreover, the peak at $1031 \mathrm{~cm}^{-1}$ can be ascribed to the stretching vibration of $\mathrm{C}-\mathrm{O}$, and the $\mathrm{C}-\mathrm{Br}$ stretching vibration are about of $584.21 \mathrm{~cm}^{-1}, 536.79 \mathrm{~cm}^{-1}$ and $507.14 \mathrm{~cm}^{-1}$.

The ${ }^{1} \mathrm{H}-\mathrm{NMR}$ of M1 was shown in Fig. S2. $\dagger^{1} \mathrm{H}-\mathrm{NMR}(400$ $\left.\mathrm{MHz}, \mathrm{CDCl}_{3}\right) \delta_{\mathrm{H}}(\mathrm{ppm}): 3.80\left(3 \mathrm{H}, \mathrm{H}_{\mathrm{a}}\right), 6.83-6.90\left(6 \mathrm{H}, \mathrm{H}_{\mathrm{c}}, \mathrm{H}_{\mathrm{d}}\right)$, 7.00-7.03 $\left(2 \mathrm{H}, \mathrm{H}_{\mathrm{b}}\right), 7.28-7.31\left(4 \mathrm{H}, \mathrm{H}_{\mathrm{e}}\right)$; the ${ }^{13} \mathrm{C}-\mathrm{NMR}$ of M1 was shown in Fig. S3. $\dagger{ }^{13} \mathrm{C}-\mathrm{NMR}\left(100 \mathrm{MHz}, \mathrm{CDCl}_{3}\right), \delta_{\mathrm{C}}(\mathrm{ppm}): 55.43$ (C1), 114.50 (C3), 114.99 (C9), 124.21 (C4), 127.35 (C7), 132.11 (C8), 139.64 (C5), 146.74 (C6), 156.68 (C2).

\subsection{Synthesis of poly[(9,9-dioctyl)-2,7-fluorene-co- $\mathrm{N}-4$ - methoxy-4,4'-triphenylamine] (PF-TPA)}

The synthesis of PF-TPA was carried out using a palladiumcatalyzed Suzuki coupling reaction. The synthetic routes and the chemical structures of the copolymer are shown in Scheme 1. The detailed procedure is described as follows: a mixture of 9,9-dioctylfluorene-2,7-diboronic acid bis(1,3-propanediol) ester $(0.5584 \mathrm{~g}, 1.0 \mathrm{mmol}), \mathrm{M} 1(0.430 \mathrm{~g}, 1.0 \mathrm{mmol})$ was first mixed with degassed toluene $(15.6 \mathrm{~mL})$ to form a clear solution. Then, tetrakis(triphenylphosphine) palladium $\left[\mathrm{Pd}\left(\mathrm{PPh}_{3}\right)_{4}\right]$ $\left(0.0346 \mathrm{~g}, 3.0 \times 10^{-2} \mathrm{mmol}\right)$ and $\mathrm{Na}_{2} \mathrm{CO}_{3}$ solution $(15.6 \mathrm{~mL}, 3.0$ mol L ${ }^{-1}$ ) was added and the mixture was stirred under nitrogen atmosphere at $105{ }^{\circ} \mathrm{C}$ for $48 \mathrm{~h}$. After cooling to room temperature, the reaction mixture was extracted with toluene and deionized water. After removing excess of the solvent under reduced pressure, the concentrated solution was added to the cold methanol to give a precipitate. Then, the precipitate was further purified by extraction with acetone for $36 \mathrm{~h}$ in a Soxhlet apparatus to remove the rest of the monomers and Pd catalyst. After vacuum drying treatment, the obtained product was characterized by IR spectroscopy, NMR spectroscopy with ${ }^{1} \mathrm{H}$ and ${ }^{13} \mathrm{C}$ probes and TGA analysis. In addition, the optical and electrochemical properties of the polymer were also investigated.

FTIR spectroscopy was used to analyze the presence of bonds in PF-TPA. Fig. S4† shows FTIR spectra of PF-TPA, which was tested by Magna-IR560 infrared spectrometers. It exhibits a characteristic absorption peak at $2926 \mathrm{~cm}^{-1}$. This peak is attributed to the $\mathrm{C}-\mathrm{H}$ stretching mode, which probably is associated with hydrocarbon contamination in the spectrometer. Furthermore, the broad absorption peak at 1506 and 1462 $\mathrm{cm}^{-1}$ can be attributed to the stretching of $\mathrm{C}=\mathrm{C}$ and $\mathrm{C}-\mathrm{C}$ bonds. Moreover, the peak at $1317 \mathrm{~cm}^{-1}$ can be ascribed to the stretching vibration of $\mathrm{C}-\mathrm{N}$, and the $\mathrm{C}-\mathrm{O}$ stretching vibration is about of $1242 \mathrm{~cm}^{-1}$.

The ${ }^{1} \mathrm{H}-\mathrm{NMR}$ of PF-TPA was shown in Fig. S5. $\dagger^{1} \mathrm{H}-\mathrm{NMR}(400$ $\left.\mathrm{MHz}, \mathrm{CDCl}_{3}\right) \delta_{\mathrm{H}}(\mathrm{ppm}): 0.74-0.81\left(\mathrm{t}, 6 \mathrm{H}, \mathrm{H}_{\mathrm{p}}\right), 1.07-1.26(\mathrm{~m}, J=$ $\left.7.9 \mathrm{~Hz}, 24 \mathrm{H}, \mathrm{H}_{\mathrm{j}}, \mathrm{H}_{\mathrm{k}}, \mathrm{H}_{\mathrm{l}}, \mathrm{H}_{\mathrm{m}}, \mathrm{H}_{\mathrm{n}}, \mathrm{H}_{\mathrm{o}}\right), 2.01-2.35\left(4 \mathrm{H}, \mathrm{H}_{\mathrm{i}}\right), 3.84(\mathrm{~s}$, $\left.3 \mathrm{H}, \mathrm{H}_{\mathrm{a}}\right), 6.98-6.92\left(\mathrm{~d}, J=8.4 \mathrm{~Hz}, 2 \mathrm{H}, \mathrm{H}_{\mathrm{c}}\right), 7.19-7.21\left(\mathrm{~d}, 6 \mathrm{H}, \mathrm{H}_{\mathrm{b}}\right)$, 7.56-7.58 (m, $\left.J=9.2 \mathrm{~Hz}, 8 \mathrm{H}, \mathrm{H}_{\mathrm{e}}, \mathrm{H}_{\mathrm{g}}, \mathrm{H}_{\mathrm{h}}\right), 7.73-7.75(\mathrm{~d}, J=7.8$ $\left.\mathrm{Hz}, 2 \mathrm{H}, \mathrm{H}_{\mathrm{f}}\right)$.

The ${ }^{13} \mathrm{C}-\mathrm{NMR}$ of PF-TPA was shown in Fig. S6. $\dagger{ }^{13} \mathrm{C}-\mathrm{NMR}$ (100 MHz, $\mathrm{CDCl}_{3}$ ), $\delta_{\mathrm{C}}(\mathrm{ppm}): 155.41$ (C2), 150.60 (C10), 146.15 (C6), 139.42 (C15), 138.67 (C12), 138.35 (C5), 134.09 (C11), 126.69 (C8), 126.42 (C14), 124.47 (C13), 122.04 (C4), 119.84 (C9), 118.88 (C7), 113.87 (C3), 54.47 (C1), 39.46 (C16), 30.75 (C17), 29.85 (C22), 29.03 (C19), 28.20 (C20), 28.19 (C21), 22.81 (C18), 21.56 (C23), 13.04 (C24).

GPC analysis of the PF-TPA was performed on a Malvern instrument connected with one refractive index detector (Viscotek-VE3580-RIDETECTOR) at a flow rate of $0.8 \mathrm{~mL} \mathrm{~min}^{-1}$ at 35 ${ }^{\circ} \mathrm{C}$ using THF solution and calibrated with polystyrene standard. The number-average molecular weight $\left(M_{\mathrm{n}}\right)$, weightaverage molecular weight $\left(M_{\mathrm{w}}\right)$, polydispersity (PDI) and the average degree of polymerization $(n)$ of PF-TPA was determined to be $23000,32500,1.41$ and 34.8 , respectively.

\subsection{Fabrication and measurement of the memory device}

The schematic of the ITO/PF-TPA/Al memory device is depicted in Fig. 1. The typical sandwiched configuration memory device is fabricated using the following procedure. The indium tin oxide (ITO) conductive glass substrates of dimensions $2 \mathrm{~cm} \times 1$ cm (sheet resistance $R_{\square}=6-9 \Omega \square^{-1}$ ) was employed as the bottom electrode and precleaned sequentially with the detergent, deionized water, acetone, isopropanol and methanol in an ultrasonic bath for $30 \mathrm{~min}$, respectively. Then they were dried in
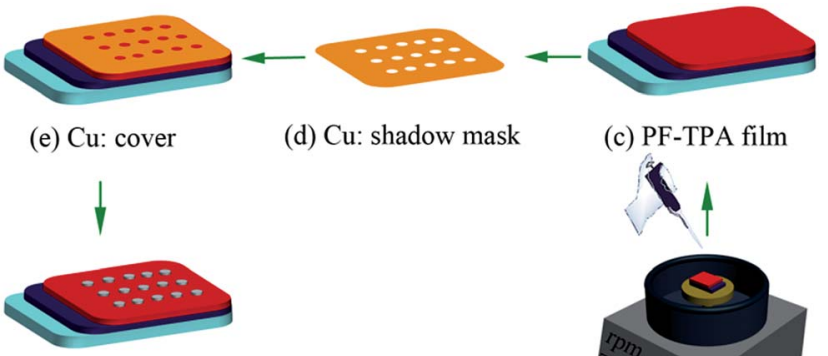

(f) Al: thermally evaporate

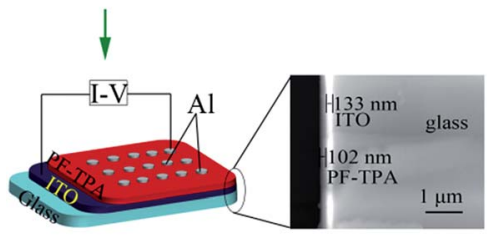

(g) Memory device

(h) Cross-section SEM
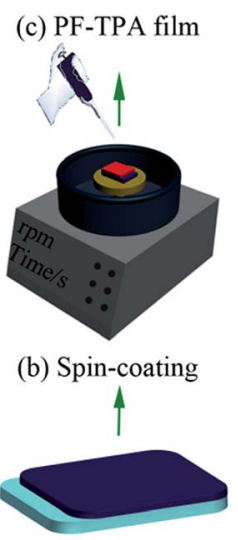

(a) ITO glass

Fig. 1 Schematic diagram of the basic fabrication procedure of the ITO/PF-TPA/Al memory device. 
a vacuum oven at $60{ }^{\circ} \mathrm{C}$ overnight. The PF-TPA was dissolved in toluene solvent ( $5 \mathrm{mg} \mathrm{mL}^{-1}$ ) with a strongly magnetic stirring at room temperature for $24 \mathrm{~h}$. After that, it was filtered through a polytetrafluoroethylene (PTFE) membrane microfilter with a pore size of $0.2 \mu \mathrm{m}$.

Then, the PF-TPA solution as an active polymer layer was spincoated onto the ITO glass substrate at a spinning speed of $900 \mathrm{rpm}$ for $15 \mathrm{~s}$ and then $3000 \mathrm{rpm}$ for $45 \mathrm{~s}$, and dried in a vacuum oven at $70{ }^{\circ} \mathrm{C}$ for $5 \mathrm{~h}$ to remove the residual solvent. Parameter settings for this procedure were beneficial to form uniform and smooth films. In the end, the $\mathrm{Al}$ top electrode layer was deposited with a thickness of $300 \mathrm{~nm}$ onto the organic film surface via vacuum thermally evaporated under high vacuum of $10^{-7}$ Torr through a shadow mask. The obtained device cells diameter is about $0.2 \mathrm{~mm}$.

The cross-section scanning electron microscope (SEM) image of the device based on PF-TPA before the evaporation of the $\mathrm{Al}$ electrode is shown in Fig. $1 \mathrm{~h}$, from the left to right show PF-TPA storage layer, ITO film and glass substrate, respectively. The thickness of the PF-TPA copolymer film can be judged as $102 \mathrm{~nm}$ from this image as measured by SEM.

\subsection{Measurements}

The IR spectra were recorded on Magna-IR560 infrared spectrometers with $\mathrm{KBr}$ pellet from $400-4000 \mathrm{~cm}^{-1}$. Nuclear magnetic resonance (NMR) spectra were recorded on a Bruker 400 spectrometer at a resonance frequency of $400 \mathrm{MHz}$ for ${ }^{1} \mathrm{H}$ and ${ }^{13} \mathrm{C}$ NMR in deuterated chloroform. Thermal properties of the samples were measured using a Netzsch STA409 thermogravimetric analyzer at a heating rate of $10^{\circ} \mathrm{C} \mathrm{m^{-1 }}$ from $50{ }^{\circ} \mathrm{C}$ to $750{ }^{\circ} \mathrm{C}$. The UV-vis absorption spectra measurements were carried out with a 756 CRT UV-Vis spectrophotometer. The PL emission and excitation spectra were obtained with a FLSP 920 full-featured fluorescence spectrometer from 350-625 nm. Cyclic voltammetry was performed on an ALS630B electrochemical analyzer with deaerated acetonitrile containing tetrabutylammonium perchlorate (TBAP, $0.1 \mathrm{M}$ ) as the electrolyte, a platinum wire as a counter electrode, an $\mathrm{Ag} / \mathrm{AgCl}$ as a reference electrode at a scan rate of $50 \mathrm{mV} \mathrm{s}^{-1}$. The current-voltage $(I-V)$ characteristic of the memory device was performed by a Keithley 4200-SCS semiconductor parameter analyzer under the ambient condition. During the measurement, the bottom electrode (ITO) was ground, and a bias voltage (from $-6.0 \mathrm{~V}$ to $+6.0 \mathrm{~V}$ ) was applied between the top (Al) and bottom (ITO) electrodes at a scan rate of $500 \mathrm{mV} \mathrm{s}^{-1}$, and the compliance current was set to $0.1 \mathrm{~A}$ to avoid breakdown of the device.

\section{Results and discussion}

\subsection{Characterization of the copolymer PF-TPA}

3.1.1 Thermal properties. The thermal properties of the PF-TPA were investigated by the thermogravimetric analysis (TGA) and corresponding differential thermogravimetric analysis (DTG). The typical TGA and DTG curves for PF-TPA were depicted in Fig. 2. During the TGA analysis using the Netzsch STA409 thermogravimetric analyzer, a ramping rate of $10{ }^{\circ} \mathrm{C}$ $\min ^{-1}$ was employed under the nitrogen atmosphere. The results of TGA analyses revealed that the PF-TPA exhibited good thermal stability. The onset decomposition temperature $\left(T_{\text {onset }}\right)$ of copolymer was recorded to be approximately $443{ }^{\circ} \mathrm{C}$. According to the DTG curve, the rapidest decomposition temperature $\left(T_{\text {rap }}\right)$ of the copolymer was about $472{ }^{\circ} \mathrm{C}$. About $45.8 \%$ weight loss was observed at $750{ }^{\circ} \mathrm{C}$ in nitrogen due to the decomposition of the alkyl and methoxy pendant groups. The results show that copolymer can provide desirable thermal properties for photoelectric device applications.

3.1.2 Optical properties. The optical properties of the copolymer were investigated by UV-vis absorption and photoluminescence (PL) spectra in the solution and solid state films. As shown in Fig. 3a, the main absorption peak is appeared at $\lambda_{\max }=382 \mathrm{~nm}$ in the solution, which might ascribe the $\pi-\pi^{*}$ transition derived from the conjugated polymer backbone. ${ }^{22}$ The optical band gap $\left(E_{\mathrm{g}}^{\mathrm{opt}}=2.95 \mathrm{eV}\right)$ was determined according to the eqn (1), where the $\lambda_{\text {onset }}(=420 \mathrm{~nm}$, as shown in Fig. $3 \mathrm{a})$ is referred to as the value of the onset absorption wavelength ${ }^{24}$

$$
E_{\mathrm{g}}=1240 / \lambda_{\text {on-set }}
$$

By applying $442 \mathrm{~nm}$ as excitation wavelength, the copolymer exhibits very strong blue fluorescence with maximum emission peak centered at $464 \mathrm{~nm}$ (Fig. 3b), in the solid thin films. The copolymer solid film will appear the $\pi-\pi$ conjugate accumulation and molecular chains aggregation due to the large number of benzene group in molecule. It makes the molecular energy gap decreases. Eventually, the emission wavelength showed a red-shift phenomenon. The fluorescence quantum yields $\left(\Phi_{\mathrm{f}}=0.61\right)$ of copolymer in THF solvents were measured by using quinine sulfate dissolved in $0.5 \mathrm{M}$ sulfuric acids as reference standard $(\Phi=$ $0.546)$.

3.1.3 Electrical properties. The cyclic voltammetry (CV) measurement was employed to investigate the oxidation and reduction properties and to estimate the highest occupied molecular orbital (HOMO) and lowest unoccupied molecular orbital (LUMO) energy levels of PF-TPA, and provide key

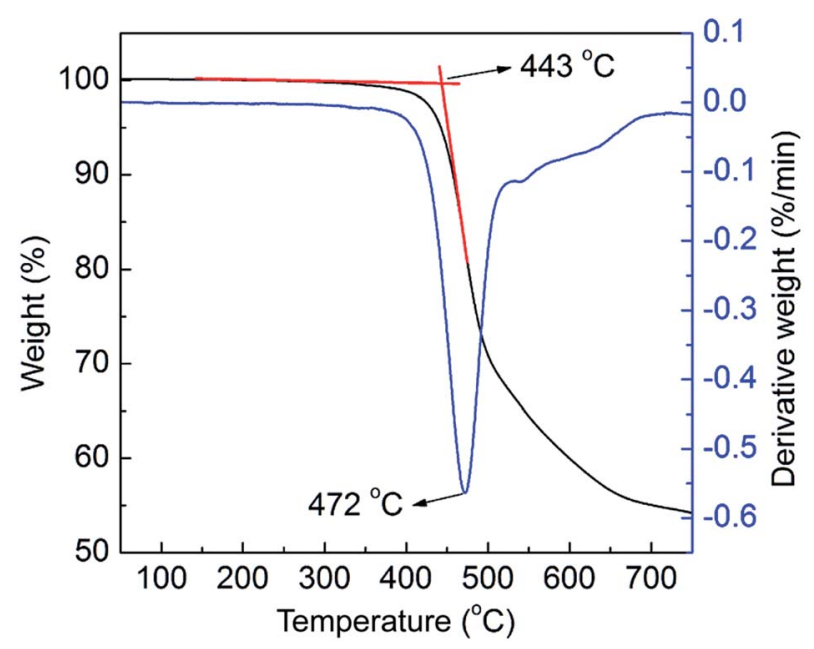

Fig. 2 TGA curve and the corresponding DTG curve of PF-TPA with a heating rate of $10^{\circ} \mathrm{C} \mathrm{min}^{-1}$. 

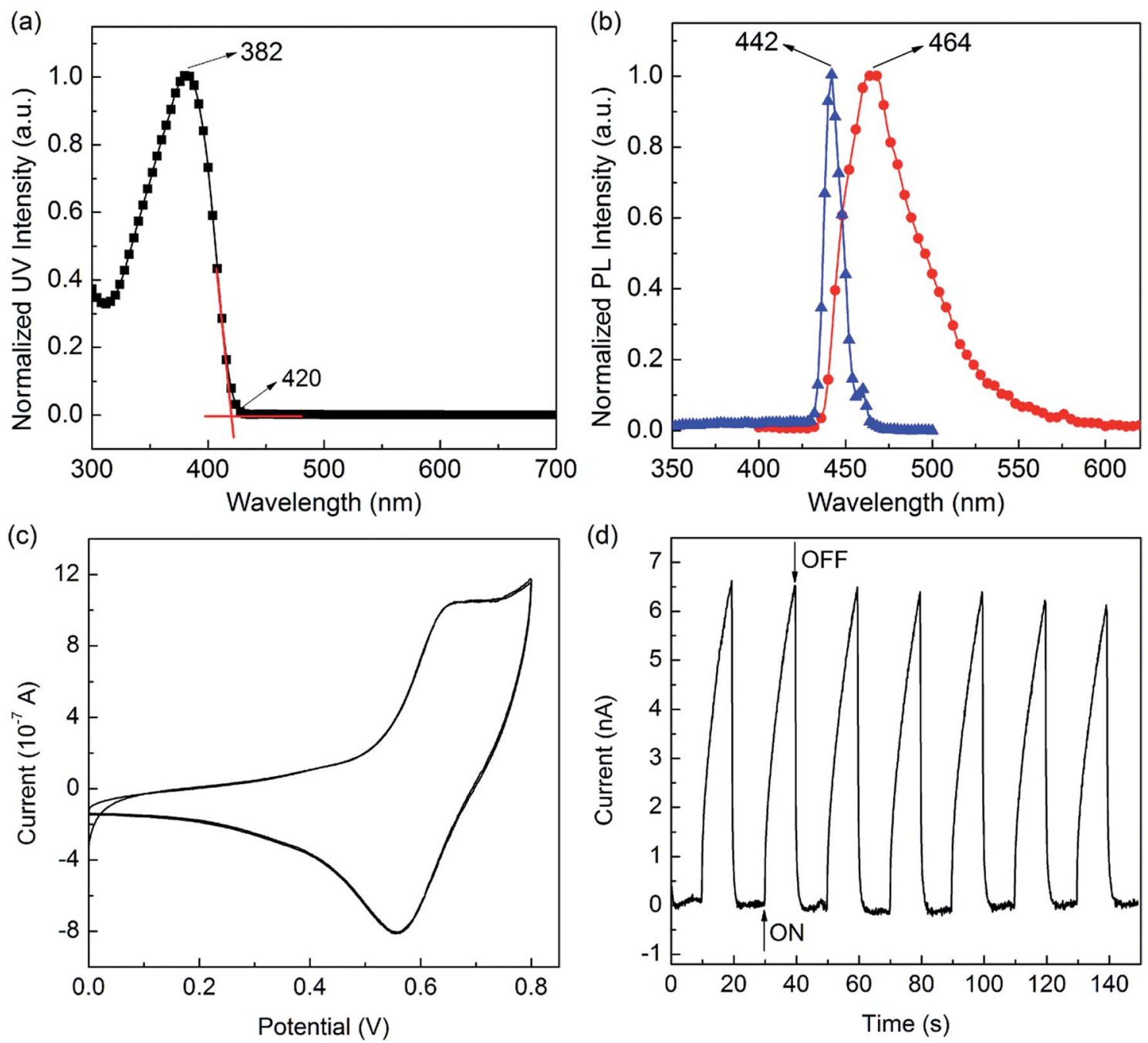

Fig. 3 (a) UV-vis absorption and (b) PL spectra of PF-TPA in the thin films. (c) Cyclic voltammetry (CV) curve of PF-TPA films onto an ITO glass substrate in $0.1 \mathrm{M} \mathrm{TBAP} / \mathrm{CH}_{3} \mathrm{CN}$. (d) Transient photocurrent responses of the PF-TPA.

parameters for the design of devices. The oxidation onset potential ( $E_{\text {onset }}$ ) was recorded at $0.54 \mathrm{~V}$ for PF-TPA versus Ag/ $\mathrm{Ag}^{+}$, as shown in Fig. 3c.

As a result, the HOMO energy value $\left(E_{\text {HOMO }}\right)$ of PF-TPA was experimentally calculated according to the eqn (2), provided that the standard ferrocene potential in the CV supporting electrolyte and the Fermi level of ferrocene at $4.8 \mathrm{eV}$ below the vacuum level are known ${ }^{23}$

$$
E_{\mathrm{HOMO}}=-\left[E_{\text {onset }}-E_{\mathrm{ox}(\text { ferrocene })}\right]-4.8 \mathrm{eV}
$$

In our electrochemical experiments, ferrocene exhibits an oxidation peak with an onset of $0.38 \mathrm{~V}$ versus $\mathrm{Ag} / \mathrm{AgCl}$. The LUMO energy value ( $E_{\text {LUMO }}$ ) level was estimated from the $E_{\text {HOMO }}$ and $E_{\mathrm{g}}^{\mathrm{opt}}$ using eqn (3), due to the accurate reduction curves could be hardly obtained.

$$
E_{\mathrm{LUMO}}=E_{\mathrm{HOMO}}+E_{\mathrm{g}}^{\mathrm{opt}}
$$

Thus, the $E_{\text {HOMO }}, E_{\mathrm{Lumo}}$ and $E_{\mathrm{g}}^{\mathrm{opt}}$ of PF-TPA were calculated to be $-4.96 \mathrm{eV},-2.01 \mathrm{eV}$ and $2.95 \mathrm{eV}$, respectively. Due to the suitable thermal stabilities, $E_{\text {Hомо }}$ value and reversible electrochemical behaviors, the PF-TPA can be used potential candidates as hole-transporting and blue light-emitting materials in emitting devices.

As shown in Fig. 3d, photocurrent transient measurements show that the current generated by the PF-TPA can be in "On" or "Off" state by turning on and off the xenon lamp at $0.5 \mathrm{~V}$ applied voltage. When the PF-TPA was illuminated by xenon lamp, the current increased sharply to the saturated current within $10 \mathrm{~s}$. When the xenon lamp was turned off, the current decreased immediately back to minimum value, i.e., recovered to the initial value in the dark. The transient photocurrent curve shows reproducibility for at least 7 times without significant change, indicating that the copolymer has a good stability and the capacity of quick response.

3.1.4 Quantum chemical analysis. The molecular simulations were carried out to get more insight into electronic structure, molecular orbitals, HOMO, LUMO and band gap of the copolymer PF-TPA. $E_{\mathrm{HOMO}}$ and $E_{\mathrm{LUMO}}$ are very popular quantum chemical parameters. These orbitals, also called the 
frontier orbitals, determine the way the molecule interacts with other species. According to the frontier molecular orbital theory, the formation of a transition state is due to an interaction between the frontier orbitals (HOMO and LUMO) of reactants. ${ }^{25} E_{\text {HOMO }}$ is often associated with the electron donating

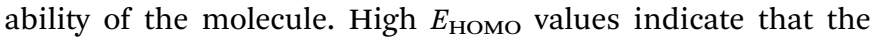
molecule has a tendency to donate electrons to appropriate acceptor molecules with low energy empty molecular orbital. Increasing values of the $E_{\text {Hомо }}$ facilitate adsorption (and therefore inhibition) by influencing the transport process through the adsorbed layer. ${ }^{26} E_{\text {LUMO }}$ indicates the ability of the molecules to accept electrons. The lower the value of $E_{\mathrm{LUMO}}$, the more probable the molecule would accept electrons. A low value of the energy band gap ( $\left.\Delta E=E_{\text {LUMO }}-\mathrm{E}_{\text {HOMO }}\right)$ gives good inhibition efficiencies, because the energy to remove an electron from the last occupied orbital will be low $^{27}$

The density functional theory (DFT) calculations were performed using the hybrid functional B3LYP with the basis set 6$31 \mathrm{G}$ for PF-TPA. First, the electronic ground state was optimized for copolymer via DFT. Then, the corresponding excitation energies were calculated, the corresponding simulation results are presented in Table 1 . The electronic cloud function of the HOMO is distributed throughout TPA part of the PF-TPA, which is good to get higher hole mobility. The electronic cloud of the LUMO is mainly localized on the fluorene portion. The HOMO, LUMO, and band gaps simulated from the B3LYP/6-31G model chemistry are $-5.04 \mathrm{eV},-2.22 \mathrm{eV}$ and $2.82 \mathrm{eV}$, respectively. The band gap $\left(E_{\mathrm{g}}=2.82 \mathrm{eV}\right)$ calculated by the molecular simulation is basically consistent with the optical band gap $\left(E_{\mathrm{g}}^{\mathrm{opt}}=2.95 \mathrm{eV}\right.$ ) estimated by the $\mathrm{CV}$ and $\mathrm{UV}$-vis absorption onset data. The slight deviation may be caused by the affection of the molecular interaction, molecular structure and solvation process. In addition, the theoretical calculation results are

Table 1 Molecular simulation result for the copolymer of the PF-TPA Frontier molecular orbital Energy level (eV)

HOMO

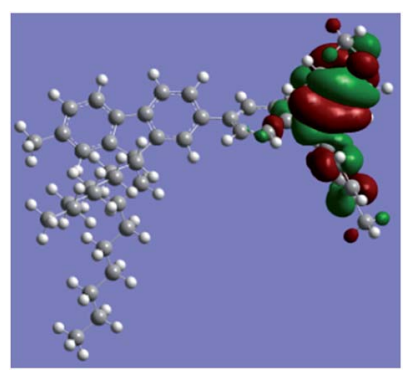

$-5.04$

LUMO

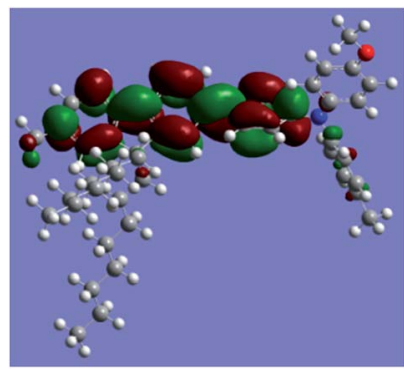

$-2.22$ based on the monomer, whereas the actual experimental measured results are in view of the entire polymer.

\subsection{Characterization of the memory device based on PF-TPA}

3.2.1 Current-voltage characteristics of memory device. The typical electrical switching and memory effect of the ITO/ PF-TPA/Al sandwich memory device is demonstrated by the current-voltage $(I-V)$ characteristic curve under ambient conditions, as shown in Fig. $4 \mathrm{a}$. In the first sweep from $0 \mathrm{~V}$ to -6 $\mathrm{V}$, the current increases slowly with the increase of the applied negative voltage sweep. Then, the current increases abruptly from $\sim 10^{-5}$ A to $\sim 10^{-2}$ A (sweep 1) when the negative sweep voltage increased to a threshold voltage of $-1.2 \mathrm{~V}$, indicating the transition of the device from the low conductivity state (i.e., OFF state) to the high conductivity state (i.e., ON state). The transition from the OFF to ON states is defined as the "writing" process in a digital memory device. In the second sweep, the device retained in the ON state during the subsequent scan from $0 \mathrm{~V}$ to $-6 \mathrm{~V}$ (sweep 2), indicating that the resistive memory effect is nonvolatile. The process is referred to as the "read" in a digital memory device. In the third sweep, a reverse bias was swept from $0 \mathrm{~V}$ to $6 \mathrm{~V}$ (sweep 3), the current returned to the OFF state in the reverse sweep as the threshold voltage approached $3.2 \mathrm{~V}$, implying its erasable feature. It can be functioned as an "erasing" process for the device. In the fourth sweep, the device was remained in the OFF state during the subsequent scan from $0 \mathrm{~V}$ to $6 \mathrm{~V}$ (sweep 4). What's more, the OFF state of the device can be switched to the ON state again when a negative sweep is applied, which suggesting that the memory device is rewritable characteristics. This completes the "write-read-erase-readrewrite" (WRER) cycle of memory device conforms that the ITO/ PF-TPA/Al has ability in an electrically bistable $I-V$ characteristic. The above processes can be repeated many times with good accuracy (sweep 5-8) for individual memory cells, despite minor variation in the write and erase voltages. Hence, the memory device exhibits a typical nonvolatile rewritable flash memory characteristic.

Fig. $4 \mathrm{~b}$ shows the relationship between the ON/OFF current ratio and the voltage for ITO/PF-TPA/Al device. It is observed that the ON/OFF current ratio is more than $10^{3}$ in the threshold voltage of $-1.2 \mathrm{~V}$. The $\mathrm{ON} / \mathrm{OFF}$ current ratio in the present device is high enough to promise a low misreading rate through the precise control of the ON and OFF states during the storage procedure.

3.2.2 Stability of ITO/PF-TPA/Al memory device. The stability performances of both the ON state and OFF state are very important for practical applications of the nonvolatile memory devices. For this reason, we investigated the effects of retention time and read pulse on the ITO/PF-TPA/Al device in the ON and OFF states under ambient conditions.

Fig. 5a shows the result of a retention performance for the electrical bistable memory device ITO/PF-TPA/Al. The stability of the ITO/PF-TPA/Al sandwich memory device was measured continuously by using a constant reading voltage of $2 \mathrm{~V}$ in ambient atmosphere at room temperature. Here, we fixed the read voltage at $2 \mathrm{~V}$ because it was not close to the threshold 
(a)

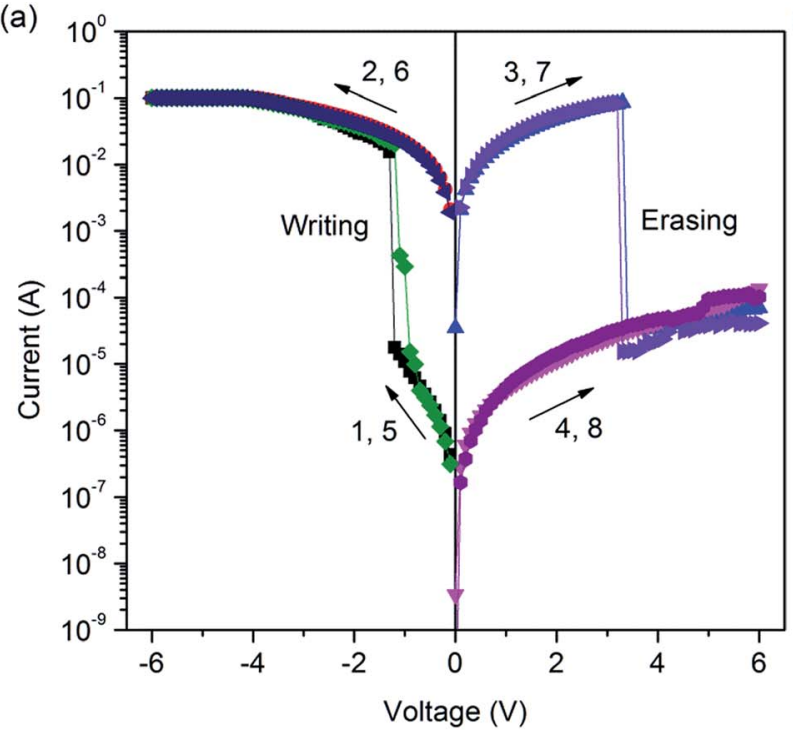

(b)

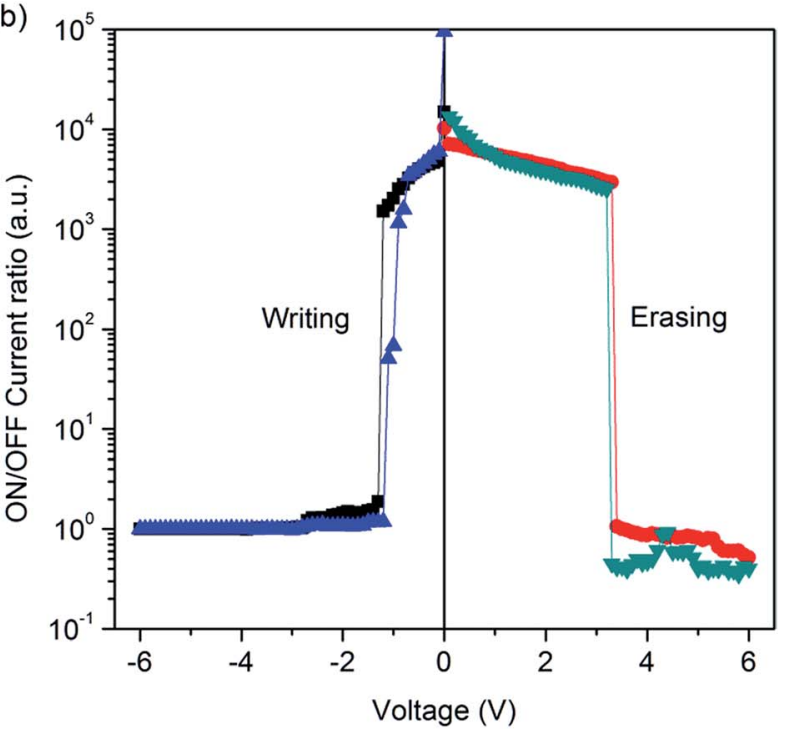

Fig. 4 (a) I-V curves of ITO/PF-TPA/Al device. (b) Relationship between the ON/OFF ratio of current and the applied voltage for ITO/PF-TPA/Al device.
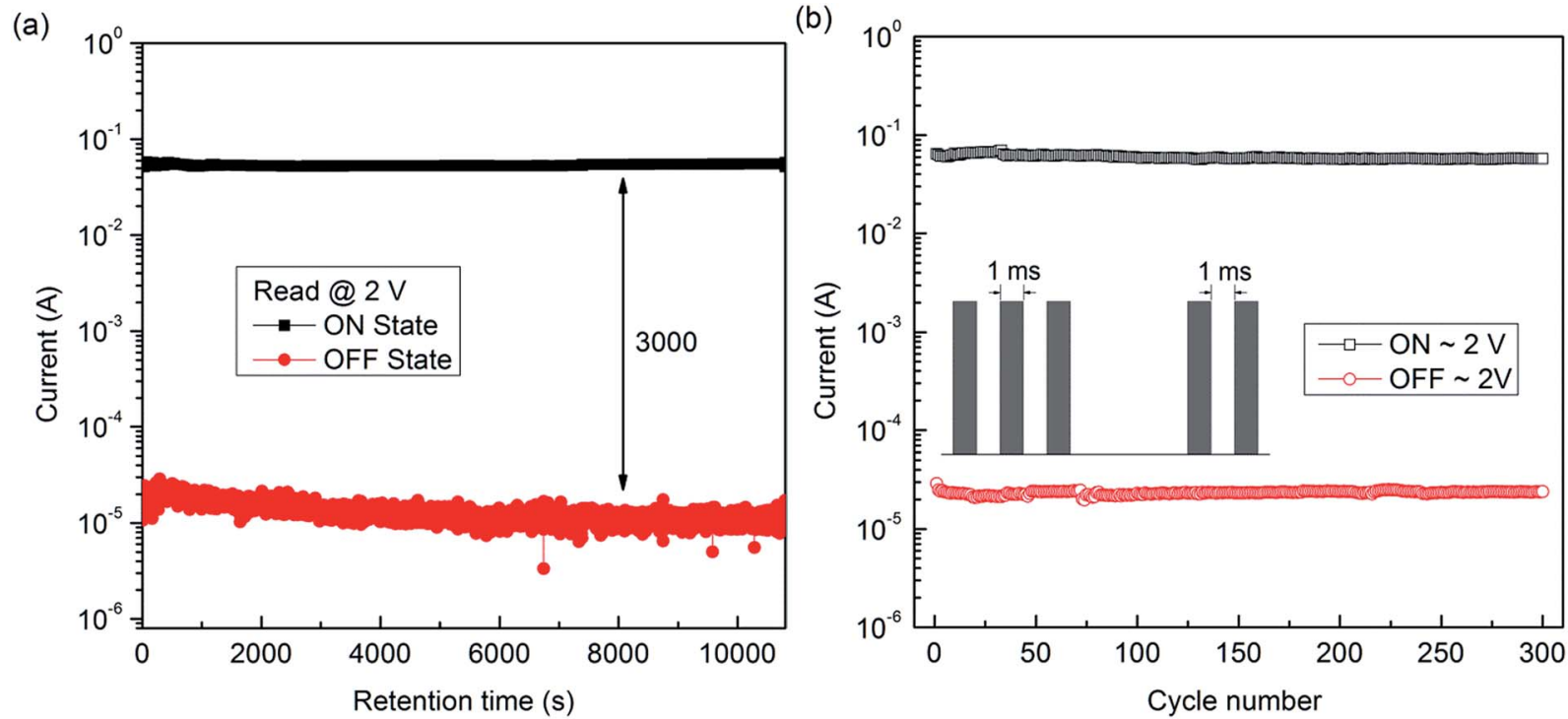

Fig. 5 (a) Retention performance of ITO/PF-TPA/Al device. (b) Stimulus effect of read pulses on the ON and OFF states of the ITO/PF-TPA/Al device. The inset shows the pulse shapes in the measurement.

voltage and had the stable performance. The ON/OFF current ratio of $3 \times 10^{3}$ can be maintained and no obvious degradation is observed during the test period of at least $3 \mathrm{~h}$, indicating that the copolymer material and electrode/copolymer interfaces have excellent stability.

As shown in Fig. 5b, the current density for the ON and OFF states remained unchanged even after more than 300 read cycles (pulse period $=2 \mathrm{~ms}$, pulse width $=1 \mathrm{~ms}$ ), indicating that both ON and OFF states were insensitive to read cycles. All these results reveal that the prototype memory device based on PFTPA copolymer has a potential application for data storage.
3.2.3 Mechanism of the ITO/PF-TPA/Al memory device. To better understand the resistive switching characteristic and current conduction mechanism of the copolymer film in the device, we researched further the preceding $I-V$ curve of the ITO/PF-TPA/Al memory device on a log-log scale, in which the slope of the fitted line contains the transport mechanism for both ON and OFF states. Fig. 6 shows the double logarithmic plot and its linear fitting of the $I-V$ curve for the set and reset process. As shown in Fig. 6, at ON state of the device, the $\log I^{-}$ $\log V$ curve has a straight line region with a slope of 1.06 (set) and 1.08 (reset), which were very close to 1 . This means that the $I-V$ data for the ON state could be satisfactorily fit using the 

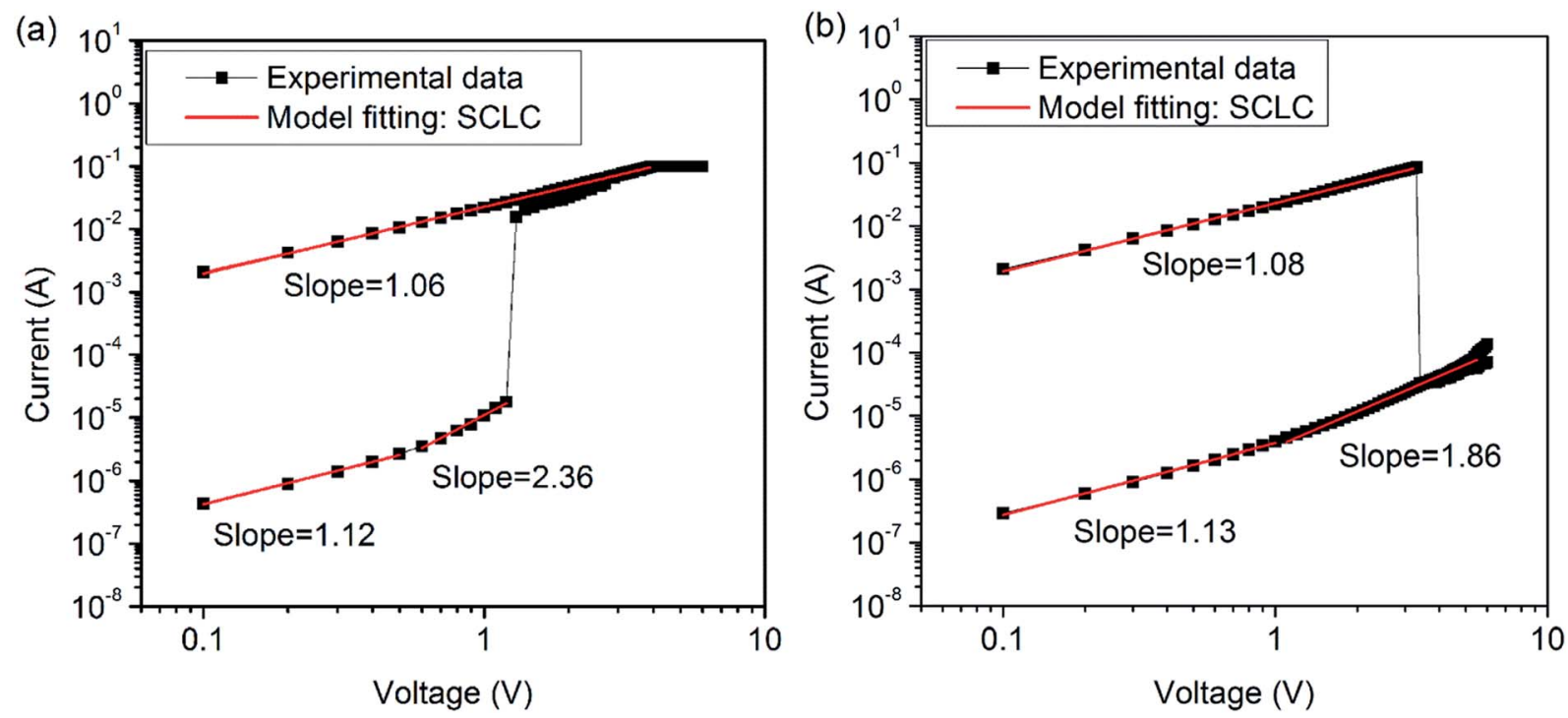

Fig. 6 Linear fitting and corresponding slopes of the I-V curves of ITO/PF-TPA/Al device. (a) Set process. (b) Reset process.

ohmic conduction model $(I \propto V)$. Moreover, the current levels of the devices in the ON state was found to be independent of the device cell size, which is indicative of the heterogeneous localized filament formation ${ }^{28}$

On the other hand, the $\log I-\log V$ plot shows an ohmic conduction behavior under a low voltage region ((a) $\leq 0.5 \mathrm{~V}$; (b) $<1.0 \mathrm{~V}$ ) for the OFF state of the device, namely, a linear proportion (with the slope of $\mathbf{1 . 1 2}$ for set process and 1.13 for reset process). Then, the $\log I-\log V$ plot gradually changes to the Child's law region (with the slope of 2.36 for set process, and 1.86 for reset process) at the high voltage region, for which the current is proportional to the square of the voltage $\left(I \propto V^{2}\right)$. This data analysis suggests that the trap-limited space-charge limited current (SCLC) conduction mechanism is probably the main conduction mechanism in the OFF state. ${ }^{29}$

Above results suggest that the excellent non-volatile memory behavior of the PF-TPA film was governed by trap-limited SCLC and local filament formation.

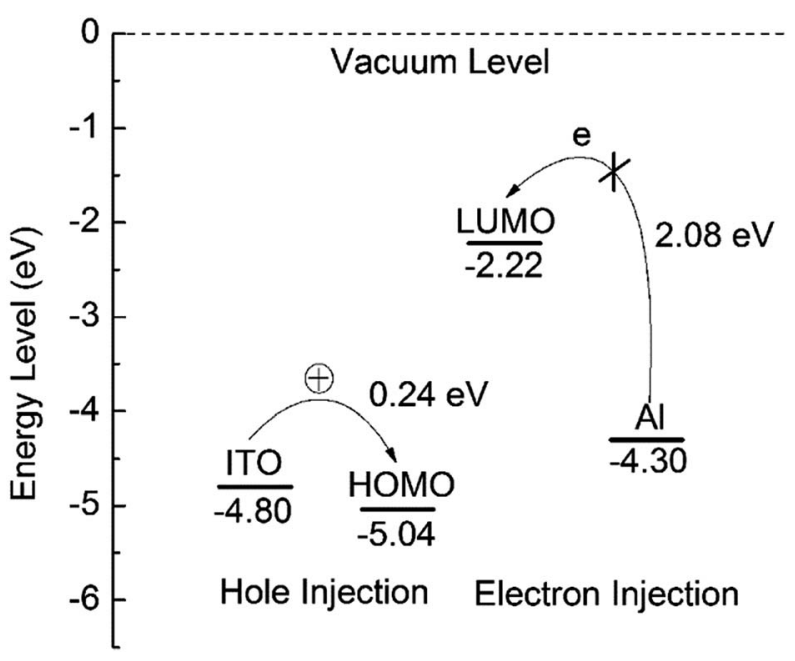

Fig. 7 Energy level diagram for the ITO/PF-TPA/Al device.
3.2.4 Stored procedure of the ITO/PF-TPA/Al memory device. The energy level diagram of the Al/PF-TPA/ITO sandwich device using the synthesized PF-TPA as the active layer is shown in Fig. 7. The energy barrier for the hole injection from the ITO electrode to the HOMO of the PF-TPA is estimated to be $0.24 \mathrm{eV}$, whereas the energy barrier for the electron injection from the Al electrode to the LUMO of the PF-TPA is 2.08 $\mathrm{eV}$, which exhibits the p-type semiconductor material characteristics. Thus, the conduction process in the device is dominated by the hole injection. Under a low negative voltage $(0 \rightarrow$ $-1.2 \mathrm{~V}$ ), holes are injected from the ITO electrode into the HOMO of the PF-TPA gradually and mobilized by hopping among the PF-TPA chains. The PF-TPA thin film displays a low-conductivity (OFF) state and the current increases slowly because the energy barrier between the Al electrode and the LUMO of the active layer is as large as $2.08 \mathrm{eV}$, which also blocks the electron migration. Theoretically, the sweeping voltage increases to the threshold voltage $(-1.2 \mathrm{~V})$ will provide enough energy for the electrons on $\mathrm{Al}$ electrode to overcome the energy barrier $(2.08 \mathrm{eV})$ between $\mathrm{Al}$ and the LUMO to inject into the active layer of the sandwich device, the injected carriers increase exponentially, resulting in the abrupt current transition ("writing" process). With the further increase of bias, the holes and electrons have a high enough mobility to form a conductive filament from the Al electrode to the ITO electrode. Hence, the current can flow through the filament and sustain the ON state.

When the reverse applied voltage increases above the reset voltage (approached $3.2 \mathrm{~V}$ ), the injected charge exceeds the capacity of the filament, and the excess current generates heat. At the same time, the repulsive coulombic interactions among the trapped charges in the PF-TPA active layer and the Al electrode may be caused by the excess current. The heat and Coulomb repulsion can rupture the filament formed in the SET process, switching the device returns to its initial OFF state (i.e., "erasing" process). 


\section{Conclusions}

In summary, we have successfully synthesized the conjugated alternating copolymer (PF-TPA) by Suzuki coupling reaction. This active material exhibited excellent thermal stability, optical properties as well as electric characteristics. Then, we fabricated the non-volatile electrical bistable resistive memory devices utilizing organic semiconductor thin film layer (PF-TPA) by using a spin-coating method. Based on the experimental results, the as-fabricated ITO/PF-TPA/Al sandwich memory device exhibited typical electrical conductance switching behavior and non-volatile rewritable flash memory effects. The device has a great ON/OFF state current ratio (greater than $10^{3}$ at $-1.2 \mathrm{~V})$ and a low threshold voltage $\left(V_{\text {SET }} \sim-1.2 \mathrm{~V}\right.$ and $V_{\text {RESET }}$ $\sim 3.2 \mathrm{~V}$ ), that promise a low misreading rate and fast response, respectively. Moreover, the retention characteristic test showed that the ITO/PF-TPA/Al device is very stable under a constant voltage stress of $2 \mathrm{~V}$ for up to $3 \mathrm{~h}$. And no degradation in current was observed for the ON and OFF states after more than 300 continuous read cycles at $2 \mathrm{~V}$ pulse. In principle, the results demonstrate that PF-TPA is promising and reliable for resistive switching devices for next generation high density storage media.

\section{Acknowledgements}

The authors are grateful to the support of the National Science Foundation of China (51527804, 51473056, 51503058, 51573015, 61471159), and Post-graduate Innovative Research Program of Heilongjiang University (YJSCX2015-080HLJU).

\section{Notes and references}

1 (a) G. F. Tian, S. L. Qi, F. Chen, L. Shi, W. P. Hu and D. Z. Wu, Appl. Phys. Lett., 2011, 98, 203302; (b) P. Wang, S. J. Liu, Z. H. Lin, X. C. Dong, Q. Zhao, W. P. Lin, M. D. Yi, S. H. Ye, C. X. Zhu and W. Huang, J. Mater. Chem., 2012, 22, 9576-9583; (c) C. J. Chen, Y. C. Hu and G. S. Liou, Chem. Commun., 2013, 49, 2804-2806.

2 (a) Y. Q. Li, H. H. Xu, X. Tao, K. J. Qian, S. Fu, S. J. Ding and Y. Z. Shen, Polym. Int., 2011, 60, 1679-1687; (b) L. Shi, N. F. Jia, L. S. Kong, S. L. Qi and D. Z. Wu, Macromol. Chem. Phys., 2014, 215, 2374-2388; (c) W. B. Zhang, C. Wang, G. Liu, J. Wang, Y. Chen and R. W. Li, Chem. Commun., 2014, 50, 11496-11499.

3 (a) T. Kurosawa, T. Higashihara and M. Ueda, Polym. Chem., 2013, 4, 16-30; (b) C. Y. Zhang, J. H. He, C. J. Lu, Q. F. Gu, L. X. Wu, Q. Liu, H. Li, Q. F. Xu and J. M. Lu, Polymer, 2015, 70, 343-350; (c) Y. Zhou, S. T. Han, Y. Yan, L. Zhou, L. B. Huang, J. Q. Zhuang, P. Sonar and V. A. L. Roy, Sci. Rep., 2015, 5, 10683.

4 (a) J. J. Kim, B. Cho, K. S. Kim, T. Lee and G. Y. Jung, Adv. Mater., 2011, 23, 2104-2107; (b) Y. Q. Li, Y. Y. Chu, R. C. Fang, S. J. Ding, Y. L. Wang, Y. Z. Shen and A. M. Zheng, Polymer, 2012, 53, 229-240; (c) Y. Kim, D. Yoo, J. Jang, Y. Song, H. Jeong, K. Cho, W. T. Hwang, W. Lee, T. W. Kim and T. Lee, Org. Electron., 2016, 33, 48-54.
5 D. Wei, J. K. Baral, R. Österbacka and A. Ivaska, J. Mater. Chem., 2008, 18, 1853-1857.

6 (a) S. G. Hahm, T. J. Lee, D. M. Kim, W. Kwon, Y. G. Ko, T. Michinobu and M. Ree, J. Phys. Chem. C, 2011, 115, 21954-21962; (b) A. Suresh, G. Krishnakumar and M. A. G. Namboothiry, Phys. Chem. Chem. Phys., 2014, 16, 13074-13077.

7 (a) B. Lei, W. L. Kwan, Y. Shao and Y. Yang, Org. Electron., 2009, 10, 1048-1053; (b) C. Chakraborty, M. K. Bera, U. Rana and S. Malik, Chem. Commun., 2015, 51, 1312313126.

8 (a) D. I. Son, T. W. Kim, J. H. Shim, J. H. Jung, D. U. Lee, J. M. Lee, W. Il Park and W. K. Choi, Nano Lett., 2010, 10, 2441-2447; (b) S. L. Qi, H. Iida, L. L. Liu, S. Irle, W. P. Hu and E. Yashima, Angew. Chem., Int. Ed., 2013, 52, 1049-1053.

9 Y. M. Sun, J. G. Lu, C. P. Ai and D. Z. Wen, Phys. Chem. Chem. Phys., 2016, 18, 11341-11347.

10 (a) C. L. Liu, J. C. Hsu, W. C. Chen, K. Sugiyama and A. Hirao, ACS Appl. Mater. Interfaces, 2009, 1, 1974-1979; (b) J. E. Park, J. H. Eom, T. Lim, D. H. Hwang and S. Pyo, J. Polym. Sci., Part A: Polym. Chem., 2012, 50, 2188-2193.

11 (a) T. W. Kim, D. F. Zeigler, O. Acton, H. L. Yip, H. Ma and A. K. Y. Jen, Adv. Mater., 2012, 24, 828-833; (b) L. Zhang, Y. Li, J. Shi, G. Q. Shi and S. K. Cao, Mater. Chem. Phys., 2013, 142, 626-632.

12 (a) D. M. Kim, S. Park, T. J. Lee, S. G. Hahm, K. Kim, J. C. Kim, W. Kwon and M. Ree, Langmuir, 2009, 25, 11713-11719; (b) J. H. Wu, H. J. Yen, Y. C. Hu and G. S. Liou, Chem. Commun., 2014, 50, 4915-4917.

13 A. Thakre, H. Borkar, B. P. Singha and A. Kumar, RSC Adv., 2015, 5, 57406-57413.

14 (a) A. Garcia, R. C. Bakus II, P. Zalar, C. V. Hoven, J. Z. Brzezinski and T. Q. Nguyen, J. Am. Chem. Soc., 2011, 133, 2492-2498; (b) K. M. Schelkle, M. Bender, K. Jeltsch, T. Buckup, K. Mîllen, M. Hamburger and U. H. F. Bunz, Angew. Chem., Int. Ed., 2015, 54, 14545-14548.

15 (a) S. H. Wang, M. Kappl, I. Liebewirth, M. Müller, K. Kirchhoff, W. Pisula and K. Müllen, Adv. Mater., 2012, 24, 417-420; (b) Y. X. Zhu, Z. H. Chen, Y. Yang, P. Cai, J. W. Chen, Y. Y. Li, W. Yang, J. B. Peng and Y. Cao, Org. Electron., 2015, 23, 193-198.

16 (a) S. H. Oh, S. I. Na, J. Jo, B. Lim, D. Vak and D. Y. Kim, Adv. Funct. Mater., 2010, 20, 1977-1983; (b) E. W. Zhu, J. F. Hai, Z. X. Wang, B. Ni, Y. H. Jiang, L. Y. Bian, F. J. Zhang and W. H. Tang, J. Phys. Chem. C, 2013, 117, 24700-24709.

17 (a) C. R. McNeill, J. J. M. Halls, R. Wilson, G. L. Whiting, S. Berkebile, M. G. Ramsey, R. H. Friend and N. C. Greenham, Adv. Funct. Mater., 2008, 18, 2309-2321; (b) D. C. Watters, H. Yi, A. J. Pearson, J. Kingsley, A. Iraqi and D. Lidzey, Macromol. Rapid Commun., 2013, 34, 11571162.

18 (a) B. Y. Hsieh and Y. Chen, J. Polym. Sci., Part A: Polym. Chem., 2009, 47, 833-844; (b) L. P. Lu, D. Kabra, K. Johnson and R. H. Friend, Adv. Funct. Mater., 2012, 22, 144-150.

19 (a) T. W. Kim, S. H. Oh, H. Choi, G. Wang, H. Hwang, D. Y. Kim and T. Lee, Appl. Phys. Lett., 2008, 92, 253308; (b) 
H. C. Wu, A. D. Yu, W. Y. Lee, C. L. Liu and W. C. Chen, Chem. Commun., 2012, 48, 9135-9137.

20 Y. Ma, X. B. Cao, G. Li, Y. Q. Wen, Y. Yang, J. X. Wang, S. X. Du, L. M. Yang, H. J. Gao and Y. L. Song, Adv. Funct. Mater., 2010, 20, 803-810.

21 (a) C. Q. Ye, Q. Peng, M. Z. Li, J. Luo, Z. M. Tang, J. Pei, J. M. Chen, Z. G. Shuai, L. Jiang and Y. L. Song, J. Am. Chem. Soc., 2012, 134, 20053-20059; (b) B. Zhang, Y. Chen, G. Liu, L. Q. Xu, J. N. Chen, C. X. Zhu, K. G. Neoh and E. T. Kang, J. Polym. Sci., Part A: Polym. Chem., 2012, 50, 378-387; (c) Y. G. Ko, D. M. Kim, K. Kim, S. Jung, D. Wi, T. Michinobu and M. Ree, ACS Appl. Mater. Interfaces, 2014, 6, 8415-8425; (d) H. B. Ye, G. F. Tian, L. Shi, S. L. Qi and D. Z. Wu, Eur. Polym. J., 2015, 63, 45-57.

22 (a) G. S. Liou, S. M. Lin and H. J. Yen, Eur. Polym. J., 2008, 44, 2608-2618; (b) A. Bolognesi, P. Betti, C. Botta, S. Destri, U. Giovanella, J. Moreau, M. Pasini and W. Porzio, Macromolecules, 2009, 42, 1107-1113; (c) K. L. Wang, M. K. Leung, L. G. Hsieh, C. C. Chang, K. R. Lee, C. L. Wu, J. C. Jiang, C. Y. Tseng and H. T. Wang, Org. Electron., 2011, 12, 1048-1062.

23 (a) Y. Lin, T. L. Ye, Y. Chen, D. G. Ma, Z. K. Chen, Y. F. Dai and Y. X. Li, J. Polym. Sci., Part A: Polym. Chem., 2010, 48, 5930-5937; (b) L. Li, T. Q. Hu, C. R. Yin, L. H. Xie, Y. Yang, C. Wang, J. Y. Lin, M. D. Yi, S. H. Ye and W. Huang, Polym. Chem., 2015, 6, 983-988.
24 (a) J. W. Cai, H. J. Niu, C. Wang, L. N. Ma, X. D. Bai and W. Wang, Electrochim. Acta, 2012, 76, 229-241; (b) C. N. Chuang, C. Y. Chang, C. L. Chang, Y. X. Wang, Y. S. Lin and M. Leung, Eur. Polym. J., 2014, 56, 33-44.

25 P. Mourya, S. Banerjee and M. M. Singh, Corros. Sci., 2014, 85, 352-363.

26 (a) A. A. Nazeer, N. K. Allam, A. S. Fouda and E. A. Ashour, Mater. Chem. Phys., 2012, 136, 1-9; (b) M. Özcan, I. Dehri and M. Erbil, Appl. Surf. Sci., 2004, 236, 155-164.

27 (a) D. B. Hmamou, R. Salghi, A. Zarrouk, M. R. Aouad, O. Benali, H. Zarrok, M. Messali, B. Hammouti, M. M. Kabanda, M. Bouachrine and E. E. Ebenso, Ind. Eng. Chem. Res., 2013, 52, 14315-14327; (b) M. Akhtaruzzaman, H. N. M. E. Mahmud, A. Islam, A. E. Shafei, M. R. Karim, K. Sopian, L. Y. Han and Y. Yamamoto, Mater. Chem. Phys., 2013, 142, 82-86.

28 (a) K. Kim, H. J. Yen, Y. G. Ko, C. W. Chang, W. Kwon, G. S. Liou and M. Ree, Polymer, 2012, 53, 4135-4144; (b) T. J. Lee, Y. G. Ko, H. J. Yen, K. Kim, D. M. Kim, W. Kwon, S. G. Hahm, G. S. Liou and M. Ree, Polym. Chem., 2012, 3, 1276-1283.

29 (a) H. Baek, C. Lee, J. Park, Y. Kim, B. Koo, H. J. Shin, D. Y. Wang and J. H. Cho, J. Mater. Chem., 2012, 22, 46454651; (b) Y. J. Huang, S. C. Chao, D. H. Lien, C. Y. Wen, J. H. He and S. C. Lee, Sci. Rep., 2016, 6, 23945.

30 B. L. Hu, C. Y. Wang, J. Zhang, K. Qian, P. S. Leea and Q. C. Zhang, RSC Adv., 2015, 5, 77122-77129. 